\title{
Reading as Critical Thinking
}

\author{
Dr. Ibrahim Abu Shihab \\ Assistant Prof. Applied Linguistics, Department of English Language, Literature and Translation \\ Alzaytounah Private University, Jordan \\ E-mail: ibrashihab@yahoo.com
}

Received: February 21, $2011 \quad$ Accepted: March 30, $2011 \quad$ doi:10.5539/ass.v7n8p209

\begin{abstract}
Reading involves an interactive process in which the reader actively produces meaning through a set of mental processes. There is obviously an ongoing interaction between the reader and the text. Critical reading is related to thinking and that is why we cannot read without thinking. Critical reading involves the following skills: predicting, acknowledging, comparing, evaluating and decision-making. Schemata can be seen as the organized background knowledge, which leads the reader to expect and predict aspects in their interpretation of discourse.
\end{abstract}

Keywords: Interactive, Critical, Reading, Thinking, Skills, Interpretation, Discourse

\section{Introduction}

Reading is a sophisticated activity, which includes psychological, linguistic, and sociological aspects. It is an interactive process between a reader and text. The process of reading involves constructing meaning among the parts of the text and between the text and readers' personal experience. The reader takes the text and gives it meaning. Both reader and writer use background knowledge to construct a text. Carrel (1987) talks about reading as an interactive process between the reader and the text. Meaning does not just reside in the text; it is rather constructed out of the interaction between a reader's background knowledge and what is in the text.

Schemata and critical thinking perform an elaborative function in comprehension when we use our knowledge to make inference. While reading a text readers fill in gaps either in things they do not comprehend or in things that are not in the text. Perkins argues that information is actually present in a text and such information could be logically inferred from the content of the text (cited in Lee, and VamPatten, 1995: 193).

\section{Related Literature}

The term "reading" has been used differently by different authors. According to Spiro (1977), Brewer and Treyens (1981), reading is "a multilevel interactive process; that is, the text must be analyzed at various levels, with units of analysis going from the letter to the text as a whole". In addition to processing the explicit features of the text (referred to as cohesion), the reader must bring considerable pre-existing knowledge to the reading comprehension process. The interaction of text-based and knowledge-based processes is essential to reading comprehension. Because the meaning of text is only partially determined by the text itself, reading must be an inferential constructive process.

Anderson and Pearson (1984) define reading comprehension in terms of the interaction between old and new information. One aspect of comprehension of particular importance to reading comprehension is the issue of how the reader's schema or knowledge already stored in memory functions in the process of interpreting new information. Goodman and Burke (1973) characterize the reading process as "psycholinguistic guessing game", whereby the efficient reader is actively involved in making and remaking a hypothesis about the writer's message (cited in Mackay et al, 1979: 6). Goodman (1976) argues that reading is a psycholinguistic guessing game that involves "an interaction between thought and language." Efficient reading is not only the result of precise perception and identification of all elements in the text, but rather from the reader's skill to produce the right guesses as with regards to the meaning of unfamiliar words and main ideas in the text (2). Goodman (1976) notes that the reader's psycholinguistic guessing game is based on his humble syntactic and semantic knowledge of the foreign language (4).

Comprehension requires the reader to go beyond the information given. Even the most mundane texts require the reader to go beyond what is explicitly stated in order to make sense of them though we are normally unaware of the extent of such interpretation in our everyday reading. Texts are full of indeterminacies, which require the 
reader's active interpretation. We must draw not only on our knowledge of language, but also on our knowledge of the world. Foreign language reading constitutes an interactive process between the reader and the text. The reader interacts with the text to create meaning as the reader's mental processes work together at different levels. Singhal (1998) defines reading as a meaning making process including an interaction between the reader and the text. Readers use mental activities to construct meaning from the text. "They should produce a reasonable hypothesis about the text he is going to read by making use of resources that he has such as common sense, general knowledge and experience, which he already has." (Nuttal, cited in Peker, 1998: 242).

Readers use various strategies for reading a text. Not only do the reader's ability and static characteristics of the text determine his or her comprehension of the text, but also the structural, syntactic, and semantic signals in the text affect that comprehension. A reader may look through a text and find relevant stations based on world knowledge and skip over seemingly irrelevant sections. Lee and VamPatten (1995) state that reading is a mental activity during which textual elements are taken in and acted on by linguistic processes mediated by the individual reader's characteristics.

Vocabulary is considered as a major component of reading comprehension. Harmon, et. al (2010) stated that a lack of vocabulary knowledge obviously limits students' understanding of a text and also hinders their ability to comprehend texts. Text structure also affects reading comprehension. Texts can be analyzed into two levels. At the micropropositional level, analysis of the text is concerned with the way sentences cohere and are organized within a text (Halliday and Hasan 1976; Van Dijk 1976). At the macropropositional level, the concern is with the relationship of the ideas represented in complexes of propositions in texts. The relationships are logical or rhetorical (Pearson 1984) and relate to the types of logical relations which operate in the text (Beaugrand 1980).

It is important to bear in mind that reading presents a gap between the writer and the reader. To fill this gap, readers need the necessary skills and strategies to be able to cope with any kind of reading text, and bridge this gap. Munby (1978) states that the process of reading requires the reader to equip himself with a number of skills he or she needs to apply. As a text is read, there is a large cognitive load on the reader as he or she is decoding the text and incorporating the textual information into his or her knowledge base.

Background knowledge is another factor which affects reading comprehension. Readers who belong to a certain cultural group will understand meanings which will be misunderstood by another group. A reader's background knowledge permits the information to be incorporated into pre-existing knowledge structures. So readers who do not have an adequate amount of background knowledge on a text will have lower comprehension (Voss et al. 1980). The background knowledge permits the reader to bridge between non-coherent sections and additional elaborative inferences.

\section{The Writing - Reading Relationship}

Once it is realized that the reading process involves an interaction between the reader, the text, and the writer, the task of developing reading comprehension becomes that of a cognitive response rather than a mechanical one. In fact, much of the recent research in both first and second language reading addressed the importance of metacognitive awareness for successful reading. The term metacognition refers to the understanding of knowledge. This understanding involves two aspects of cognition, the reader's knowledge of strategies for learning from texts, i.e., knowing the necessary skills to prepare for a test and knowing when one is ready to be tested, and the control the reader has of his own actions while reading for different purposes. The latter regulatory activities check and evaluate ongoing comprehension and determine the nature of strategic action to follow.

Anderson (2002) points out that the use of metacognitive strategies activates one's thinking and leads to improve performance in general.Coşkan (2010:35) states that learners who have metacognitive awareness seem to have the following advantages over others:

1. They are confident in their abilities to learn.

2. They do not hesitate to obtain help from others.

3. They provide accurate assessments of why they are successful learners.

4. They think clearly about inaccuracies when failure occurs during an activity.

Thus, competent readers do not only interact with texts differently, but also monitor and evaluate the state of their comprehension. When necessary, they take appropriate strategic action. Calkins (1983) states that writing and reading share common behaviors. Both writing and reading are transactional processes in which the writer/ reader interact with the text (Shanklin 1981; Smith 1982). 
Baker \& Brown, (1984) defines metacognitive awareness as "knowledge about ourselves, the tasks we face, and the strategies we employ." The reader unconsciously employs such knowledge to evaluate his perception and comprehension of the text and the text difficulty level. Metacognitive awareness involves the reader's awareness of whether or not comprehension is occurring, and the conscious application of one or more strategies to correct comprehension (Baumann et al (1993). Khun (2000:178) assures that metacognition enhances (a) metacognitive awareness of what one believes and how one knows and (b) metastrategic control in application of the strategies that process new information.

Foreign language learners employ several cognitive strategies while reading in a foreign language classroom. Such cognitive strategies include note taking, summarizing, paraphrasing, predicting, analyzing, and using context clues. Research on cognitive strategies has discerned several types that range from the simple to the most complex. Memory cognitive strategies help the reader remember and retrieve information. These include creating mental images, chunking, semantic mapping, and word associations. Compensation cognitive strategies include inference, guessing the meanings of unfamiliar words from the context and their linguistic and semantic clues, and skilful use of monolingual dictionaries (Singhal, 2001:3). Previous research has found out that metacognitive strategies enhance foreign language readers' comprehension. Karbalaei (2010) investigates whether there are any significant differences between EFL from Iran and ESL from India in metacognitive reading strategies when reading academic texts in English. The result of this study indicates that the subjects in both groups report a similar pattern of strategy awareness while reading academic texts although the two student groups have been schooled in significantly different socio-cultural environments. Leavitt (2010) investigates the use of the Miscue Coding for Metacognitive Strategies (MCMS) amongst students of French from the University of Notre Dame and Indiana University South Bend to assess their use of metacognitive reading strategies as tools for comprehension. Results showed that metacognitive reading strategies, though can not be measured, have significantly improved the students' reading comprehension. Iwai (2009) explored the role of metacognitive awareness in reading among ESL students of various academic levels enrolled in a university in the southeastern part of the United States of America while engaged in academic reading. Results showed that students were aware of metacognitive reading strategies when engaged in academic reading. Key reading strategies used by these students included adjusting reading speed and selecting strategies for different purposes, using prior knowledge, inferring text, marking text, focusing on typographical features, and summarizing. Results also indicates that the participants used similar strategies in both $\mathrm{L} 1$ and $\mathrm{L} 2$ reading.

The reader must have extraordinary linguistic competence (semantic, syntactic, and graphonemic systems), a knowledge of the story or topic being read, and an understanding of what has happened previously in the story (Goodman and Burke, 1973). These previously stated factors, in addition to the reader's skill of how to read, are termed by Smith (1982) the nonvisual information, which is essential for reducing uncertainty in advance and to make decisions with less visual information.

According to Koda (2005), the strategic reader is one who monitors the reading process carefully, takes immediate steps when encountering comprehension problems, is aware of his or her own cognitive and linguistic resources and is capable of directing attention to the appropriate clue in anticipating, organizing, and retaining text information (204). Grabe (2009) calls this metacognitive awareness as metalinguistic analysis, which entails the reader's "ability to use metalinguistic knowledge to carry out tasks," (132).

Writers cannot be totally creative. They can only produce their own text either by making use of other texts written previously in similar social contexts, or they may choose to make use of other texts used in different social contexts. Written texts have communicative purpose, allowing the writer to share ideas, experience, and feelings with an audience. Texts have a communicative potential since they can be viewed as

a conversation or interaction, which goes on between the writer and reader. An acceptable text not only has cohesion, but also has coherence, or organizational and rhetorical features which make it meaningful.

One difference in reading and writing lies in the realization of the text. In writing, the text is originated in the mind of the writer and is realized in the graphic display produced; while in reading, the realization occurs in the mind of the reader. Tierney and Pearson (1983) state that meaning is created as the reader reads and is aided by the author's cues in the text just as meaning is created as the writer writes and is aided by the developing text. Reading is a silent activity involving an interactive process between the reader and the writer. Grellet (1981) states "Understanding a written text means extracting the required information from it as efficiently as possible." (3) 


\section{Schema Theory and Critical Thinking}

Reading involves an interactive process in which the reader actively produces meaning through a set of mental processes. There is obviously an ongoing interaction between the reader and the text. Reading without thinking is not possible. Reading a text activates memory nods, which represent previously stored knowledge. Memory nods are the building blocks of mental structure, which are built by mapping incoming information such as sentences onto a mental structure. Comprehension involves the mental processes, which are different from one reader to another. Van Dijk (1981) states that schemata are "higher-level complex and even conventional or habitual knowledge structures" (141) which function as "ideational scaffolding" (Anderson 1977) in the ordering, organization and interpretation of experience. Schemata are considered to be necessary for regulating and organizing the reader's reading experience and his ability to interpret the meaning of the text.

Schemata constitute the organized background knowledge which helps readers expect or predict aspects in their interpretation of a text. A schema is a hypothetical mental structure for representing generic concepts stored in memory. It is a sort of framework, or plan, or script. Schemata are created through experience with people, objects and events in the world. When we recall our school days, we begin to generalize across our school experiences to develop an abstracted, generic set of expectations about what we will encounter in a school. This is useful because if someone tells you a story about a school, they do not have to provide all of the details about the school because your schema for it can fill any missing details. Cook (1989) states, "The mind stimulated by key words or phrases in the text or by the context activates a knowledge schema" (69). Cook implies that we are not necessarily dealing with conscious processes, but rather with cognitive processes given to external stimuli. Schemata are activated in one of the following two ways:

1- New information coming from the outside world can be cognitively received and related to already known information stored in memory through retrieval or remembering. In this process, new concepts are assimilated into prior knowledge which can be altered or expanded.

2- New information can be represented by new mental structures. In this case, the absence of prior knowledge will lead to building up new schemata.

According to Plastina (1997), the individual gathers bits of knowledge together, attempting to make sense of them. In this context, schemata are seen as flexible processes; they undergo a cyclic process within changes which are brought about actively and economically i.e. information is stored in memory and provided when needed with the least amount of effort. Such schemata are creative because they can be used to represent all types of experiences and knowledge. The reader needs to think while reading and bridge his own prior knowledge and new knowledge coming from outside. Critical reading should be central to any discussion of bridging the prior knowledge with the new one. Critical reading was defined as learning to evaluate, draw inferences and find the conclusions based on the evidence.

\section{Conceptual Unity}

A text does not make sense by itself, but rather by the interaction of the text presented knowledge of the world and the reader. Coherence is clearly not a feature of texts, but rather the outcome of cognitive processes among text users. Brown and Yule (1983) state that we can think of our processing of incoming discourse as the combination of two activities. In one part of the processing, we work out the meanings of words and the structure of a sentence and build up a composite meaning for the sentence (i.e. bottom- up processing). At the same time, on the basis of the context and the composite meanings of the sentences, which have already been processed, we predict what the sentence is most likely to mean (i.e. top-down processing). The degree to which the meaning and structure of a text is made apparent to the reader depends largely on whether the reader's selected schemata, or expectations, are consistent with the text. Information in the text has to be compatible with the schema, or the system of knowledge, already existing in the mind of the reader. Meaning cannot be grasped out of a text if at least some of the ideas, values, facts, genre, language, style, etc, represented in the text have no place in the reader's knowledge repertoire.

The reader imagines himself or herself in the world of the text and uses this position to interpret the text. The readers' pre-existing background knowledge is said to be embodied in statements mentioned early in the text which serve to activate their mental schemata relevant to the topic of communication. Readers use this knowledge, and other real-world knowledge, to guide their interpretation of information correctly or incorrectly understood from the text. Schank and Bustein (1985) pointes out that language understanding is essentially a memory-based process. We interpret new stories not just in terms of our general world knowledge, but also in terms of our own related personal experiences. (146) 
In a cited experiment adapted from Kabcali (1997) two persons come from two different backgrounds, and each brings his own knowledge and experience to the text, interpreting it from their own perspective as follows: One day a foreign scholar came to the village and asked to talk to the wisest man in the town. So the villagers took him to a man. When they met, the foreigner took a stick and drew a large circle on the ground. The man looked at the circle, took the stick, and drew a line across the middle of the circle. Then the foreigner drew another perpendicular line, dividing the circle into quarters. The man gestured as though he was taking three of the sections and leaving the fourth. The foreign man put his fingers together, facing them toward the ground and shook them. The man responded by raising his hand to the sky, stretching out his fingers. When the meeting was over, the foreign scholar explained "Your man is very smart. When I indicated that the Earth was round, he responded that an equator divides it. When I divided the Earth into four sections, he said that three quarters of it is water. When I asked him what causes rain, he told me that water evaporates; vapor rises and forms clouds, and then turns into rain." Then the villagers asked the man what happened during the meeting. The man said "nonsense"! He said "I have a pan of sweet." I said that he couldn't eat it alone, and that I would eat half of it. Then he asked me what I would do if he divided it into four pieces. I said that I would take three of them. Then he said "let's sprinkle nuts on it." I said ok, but you can't bake the sweet on a weak fire; it had to be strong. He felt defeated, and went away. The foreign scholar sees the discussion as an academic one focusing on the Earth's geography; the man interprets the text as an argument about sweets. Each of these interpretations, though different, makes sense in terms of the signs and gestures. And in this case the two characters do not even know that they are miscommunicatiing. Each of them has his own perspectives.

In the text cited above four groups are represented; the man, the foreigner, the villagers, and the narrator. The man and the foreigner interpret the text each according to his prior knowledge. This has significant implications; one of which is that a text cannot carry meaning on its own, and that there may be different interpretations of the same text. It seems reasonable to assume that there is an infinite number of possible interpretations of the same text, although Kress (1989) warns us that there are social limitations to how people understand texts (42-44). Another implication is that the information in the text has to be compatible with the schemata, or the system of knowledge, already existing in the mind of the producer; otherwise, meaning cannot be obtained from a text. This is why the man and the foreigner interpret the text in different ways. The villagers play an important role, even though they have no words in the text. They are merely recipients of the story. Psychologists emphasize the text producer's intention to guide the consciousness of the hearers in this case the villagers. The narrator also has a role in the story as the one who gives the setting.

\section{Critical Discourse Analysis (CDA) and the Teaching of Reading}

Any review of the literature on the teaching of reading skills to EFL students that has appeared during the last twenty years has to include the aphorism that reading is an interactive process. No text can be considered separate from the reader; there must be a successful interaction between the reader and the discourse to be processed. The degree to which the meaning and the structure of a text is made apparent to the reader depends largely on whether the reader-selected schemata, or expectations, are consistent with the text. Girl's (1991) statement, "there is no theory of reasoning which is generally accepted as an orthodoxy" (45) could have some connections with Widdowson's (1998) perhaps rightful complaint that CDA is in need of a strong theoretical basis. Although some writers argue that learners cannot or need not be taught how to read and think, either because they merely need to experience these skills to learn them naturally (Smith 1982: 5), or because their "native language" provides them with the skills (Byrnes 1987: 178). Thinking in the above described way neither happens automatically just by exposing learners to various sorts of texts, nor could we rely much on the reading skills for various possible reasons, such as lack of reading habits, or the existence of a possible different mode of thinking.

As with regards to methodology, Floyd and Carrell (1987) state that the ESL teacher must provide the students with appropriate schemata they lack, and must also teach them how to build bridges between prior knowledge and new knowledge. Accordingly, the building of bridges between a student's prior knowledge and new knowledge needed for text comprehension is necessary for effective reading comprehension. One method that promotes critical reading involves the use of news media in the class. Newspapers, magazines, television, and radio can motivate students to develop critical listening and reading skills.

The teaching of thinking and communication skills appears to be the major strength of CDA in the classroom. We can list such thinking skills as follows: 
First, predicting is an important skill for comprehending a text; however, it is only through our existing knowledge that we can predict. That is, the more we know about the text we are about to read, the more we are able to limit our processing choices, which increase our reading efficiency.

Second, acknowledging incoming information or building textual meaning from the smallest units to the largest is an important reading skill.

Third, reading involves "checking the text", or what is called "comparing what one knows about that text and texts of that sort with the actual text".

Fourth, "confirming or refusing our predictions" suggests a confirmation or modification of our preexisting knowledge, and thus there is a need for evaluating and decision-making skills as a part of the reading process.

Fifth, reading involves an ability to shift modes of processing accommodating to the demands of a particular text and a particular reading situation, which suggests skills usually associated with intelligence, such as adaptability, practicality, and quick-thinking.(Bartu,1998:53-56)

Such points listed above are the same skills necessary for any academic inquiry: hypothesizing or identifying a problem, collecting data, analyzing the data by comparing and evaluating, confirming or refuting the hypothesis, and solving or restating the problem. If this is the case then, it may not be wrong to suggest that reading is an activity which is closely associated with thinking; therefore, it seems sensible to suggest that considering the development of thinking, or reasoning skills, should be an indispensable component of any planning for teaching reading. There is a lot to be gained from Fairclough's (1989, 1990, 1992, 1993) Critical Discourse Analysis framework. Since it follows that the more deeply we analyze a text, the more we can be critical of it, and the more efficient our reading will be for all purposes, and not just for "democratic citizenship" as Fairclough (1992: 3) suggests. Fairclough (1992) argues that every instance of language use has three dimensions; it is a spoken or written language text; it is an interaction between people involving processes of production and interpretation of this text; and it is also a social action (10-11) The relationship between social action and text is mediated by interaction; that is, the nature of the interaction, how the text is produced and interpreted depends upon the social action in which it is embedded, and the nature of the language and the style of the text depends upon and constitutes the ways in which it is produced and interpreted, also forming the social action. CDA has three dimensions: the description of the language properties of the text, the interpretation of the interaction processes and their relationship to the text by making use of our knowledge of the wider society and our knowledge of similar texts, and the explanation of how the text and the interaction processes relate to the social action, in terms of their functions and effects in the society at large

\section{Conceptual Knowledge}

There are some concepts on which CDA is based:

\section{a. Coherence}

The term coherence refers to the relationship which links the meaning of utterances in a discourse or of the sentences in a text. The said links may be based on the speakers' shared knowledge. Thus, despite the existence of no grammatical or lexical link between two utterances/ sentences, they can still have coherence as in:

\section{- Can you go to London tomorrow?}

- B. E. A. (British European Airways) are on strike (Widdowson cited in Brown and Yule 1983).

It is obvious in the above example that B's reply to A's question is simply negative. Coherence is the name given to the totality of meaning arrived at after a text is interpreted and each bit of information is logically linked to form a consistent whole. Fairclough (1993) states that this is not a property of texts, but a property which interpreters impose upon a text (134). This has as a major implication that there can be many different interpretations of the same text by different people and even by the same people at different times. Useful places to look at, to understand the writer's mode of rationality and argumentation in the text could be the ordering of the information such as which sentence comes after which, the cohesive words and phrases like "and" "however" and reference words such as "this" and "it".

The following example is to illustrate the interpretation efforts of a reader to achieve coherence "I left the garage door open today although it was sunny." In order to interpret this sentence, the reader has to work hard to try to fill in the missing information and make the links between the two parts of the sentence. The sentence would perhaps have made much more sense to the reader if the connecting word was "because" suggesting perhaps that the garage door was left open to get some dry air in, for the garage would otherwise be dump or stuffy. Another 
interpretation is because there was much oil and wax in the garage, which should not have been heated he did not want sunshine to get in through the garage door.

We can interpret linguistic messages in connection with the assumption of coherence, as in:

'Find the Ball, Win a house, P.4'.

The literal meaning of this extract does not convey the message. But in connection with the assumption of coherence, we can guess that on P.4 of the newspaper, there will be a competition with task determined by the first sentence and the prize detailed in the second. Beaugrand and Dressler (1986) define coherence as a continuity of senses and the configuration of concepts and relations. Coherence as defined by Van Dijk (1981: 268) is the "idea, upshot, or gist of a discourse." Coherence is normally achieved when sentences follow each other in a logical order and hold together with transitions.

\section{b. Intentionality}

"Intention" has become the center of interest in various disciplines. For example, psychologists emphasize the text producer's intention to guide the consciousness of the hearer while philosophers argue that a text is to produce some effect in the audience by means of the recognition of this intention. Linguistics, being affected by the philosophical approach, has focused on the question of how intentions are correlated with the format and sense of utterances. Austin (1962) suggested that in uttering a sentence, a speaker is generally involved in three different acts. First, there is the locutionary act: the act of uttering a sentence with certain meanings as in:

There are four bulls in the field

In addition, the speaker may have intended his utterance to constitute an act of praise, criticism, agreement, frightening, boasting, etc. This is so called illocutionary act. The example stated above may be used to warning (a walker who is about to cross the fence) a statement (to a fellow farmer) or a threat (to a boy who is behaving). It is difficult to define the illocutionary act (The intention of the producer) without knowing the context. The perlocutionary act is the real effect on the audience or receiver.

\section{c. Acceptability}

The notion of acceptability in the narrow sense is really useful only for texts in situation, not for isolated sentences but in a wider sense, it would subsume acceptance as the active willingness to participate in a discourse and share a goal. Successful communication clearly demands the ability to detect or infer other participant's goal on the basis of what they say. This reveals how great a role is played by the context of communication with respect intentionally and acceptability.

\section{Readers' Inferences}

In critical reading, implications of the writer are followed by inferences of the reader as the first reaction. However the reader should double check whether he has understood the main idea of the text, all the facts, and flow of actions. All the information available must be used in the inferring process. Going far beyond the information and evidence the reader has may cause a faulty conclusion. The likes, dislikes and ideas of the reader should not subjectively affect his inference. The reader should not depend on his own experiences only as if they are absolutely right. This is not a sound way to follow. In other words the reader should judge the worth of what he knows and contributes as well as questioning the writer's opinions. Conventional reading comprehension activities generally contain classical questions, however in critical reading the questions may be very different due to the implicit points or subjective approaches in the text that have to be comprehended, questioned, or judged. If such analysis is not carried out, the reader can be dragged into the area ruled by the writer and influenced heavily. Some readers never criticize what they read if the writer is very famous. Moreover, many readers, who cannot react and resist what they read through objective judgment, focus on the writer's nationality, race, religion or other personal characteristics.

The reader should fill in the missing or hidden parts of the text. Reading requires high levels of brain activity including renewing images and thoughts in the mind in relation with the contents of the text. The readers have to use the powers in the mind such as conceiving ideas, drawing inferences, and making judgments and predictions. Peker (1998) claims that it is important that we must teach learners the art of predicting and inference if we want them to get to meaning in any text that they are going to read.

Comprehension beyond the word level requires the reader not only to activate background knowledge, but also to use it in integrating meaning across sentences. As the message becomes less familiar, inference demands increase. Many poor readers have difficulty in making inferences even when they decode fluently. Yule (1986) defines inference as a piece of information, which is not directly stated in the text. The inferences are derived 
from our conventional knowledge in our culture. Schemata are conventional knowledge structures, which exist in memory and are activated in the interpretation of what we experience. Furthermore, Fernández-Valmayor, et al. (2000) state that when reading a text in L2, the reader uses inferences as the main strategy to build up the meaning of the text. Inference is a mental process, which is activated through interpretation. It is a mental activity consisting of a set of cognitive operations that allow the reader to derive certain meanings from other meanings, either through deduction or induction. Inference is, therefore, a relatively complex reasoning strategy.

Inference is a crucial factor in text processing. The rather general notion of inference is said to describe the process, which the reader must go through from the literal meaning of what is written to what the writer intended to convey in order to interpret the message successfully. In such a case inference is a process of filling in the missing links between two sentences. An example will be presented in $\underline{a}$ and $\underline{b}$ sentences (the text), and they will be linked via the information in the $\underline{\mathbf{c}}$ sentence:
a- I bought a bicycle yesterday.
b- The frame is extra large.
c- The bicycle has a frame (Chafe, cited in Brown and Yule, 1983: 257).

Noordman and Vonk (1992) state that reader's knowledge of the world is an important factor in controlling inferences, when people understand a discourse, they process its meaning and construct a mental representation of the semantic information in the discourse. Inferences controlled by the knowledge of the reader can be investigated in experiments in which the relation between the proposition that has to be inferred and the reader's model of the world is varied. The information in the proposition may or may not be part of the reader's knowledge.

\section{Conclusion}

The first aim of this paper has been to suggest that reading cannot be possible without thinking and to suggest that critical discourse analysis can be useful as an instrument in the teaching of the required thinking skills and communication, namely predicting, acknowledging, comparing, evaluating, decision-making and communicating. The article also aimed at shedding light on the sorts of reading difficulties, most notably is the lack of language knowledge that foreign language learners encounter while reading texts of various difficulties and means of overcoming them. The second aim has been to describe critical reading and its relation to schemata. Critical reading is a sophisticated game in which writers and readers interact. It is a reading skill for readers' security. A good critical reader does not let the writer twist the truth and persuade him to share his opinion. However, this does not happen automatically. He has to use his prior knowledge in order to understand the intention of the writer.

\section{References}

Anderson, N.J. (2002). The role of Metacognitive in Second Language Teaching and Learning. Modern Language Journal, 75, 460-472.

Anderson, R. (1977). The Notion of Schemata and the Educational Enterprise. In R. C. Anderson, Spiro, R. J., \& Monatague, W. E. (1977). Schooling and the Acquisition of Knowledge. (pp.415-431). Hillsdale, N.J.: Lawrence Erlbaum.

Anderson, R. and Pearson P. (1984). A Schemata Theoretic View of Basic Processes on Reading Comprehension, In P.D. Pearson. (Ed). Handbook of Reading Research. London: Longman. (255-317).

Austin, John. (1962). How to Do Things with Words. London : OUP.

Baker, L. and Brown, A. (1984). Metacognitive Skills and Reading. In D. Pearson (Ed.), Handbook of Reading Research (pp. 353-394). New York: Longman.

Bartu, H. (1998). Can't I Read without Thinking? The Second Inged-Gazi International ELT Conference Proceedings, Gazi University, 51-74.

Baumann, J. F., Jones, L.A., \& Seifert-Kessell, N. (1993). Using Think Aloud to Enhance Children's Comprehension Monitoring Abilities. The Reading Teacher, 47(3), 184-193.

Beaugrand, R. (1980). Text, Discourse and Process. Norwood, NJ: Albex.

Beaugrand, R. and W. Dressler. (1986). Introduction to Text Linguistics. London: Longman.

Brewer, W. F. and J. C. Treyens. (1981). Role of Schemata in Memory for Places' Cognitive Psychology, 13:207-30. 
Brown, G and G. Yule. (1983). Discourse Analysis. Cambridge: Cambridge University Press.

Byrnes, H. (1987). Getting a Better Reading: Initiatives in Foreign Language Reading Instruction, In SJ. Savignon and M.S Berns (eds.) Initiatives in Communicative Language Teaching II: A Book of Readings. Addison-Wesley Publishing Co. (171-204).

Calkins, L. M. (1983). Lessons from a Child. Exeter, NH: Heinemann Educational Books.

Carrell, P. (1987). Content and Formal Schemata in ESL Reading. TESOL Quarterly, 21:461-481.

Cook, G. (1989). Discourse in Language Teaching: A Schema for Teacher Education. Oxford: Oxford University Press.

Coşkun, Abdullah. (2010). The Effect of Metacognitive Strategy Training on the Listening Performance of Beginner Students. Novitas-Royal (research on Youth and Language), 4(1)35-50.

Fairclough, N. (1989). Language and Power. London: Longman.

Fairclough, N. (1990). Critical Linguistics: New Times, and Language Education, In R. Clark. N. Fairclough, R. Ivanic, N. Mcleod, J. Thomas and P. Meara (eds.) Language and Power: Papers from $22^{\text {nd }}$ Annual Meeting of the British Association of Applied Linguistics. CILT, (7-20).

Fairclough, N. (1993). Discourse and Social Change. Cambridge: Polity Press.

Fairclough, N. (Ed.) (1992). Critical Language Awareness. London: Longman.

Fernández-Valmayor, A., López-Alonso, C., Sere, A., and Fernández-Manjon, B. (2000). Integrating an Interactive Learning Paradigm for Foreign Language Text comprehension into a Flexible Hypermedia System. [Online] Available: http://e3.uci.edu/programs/ifipconf/papers/fernandez/

Floyd P. and Carrell P. (1987). Effects on ESL Reading of Teaching Cultural Content Schemata. Language Learning, 37:89-108.

Freebody, P. and Anderson, R. (1981). Effects of Differing Propositions and Locations of Difficult Vocabulary on Text Comprehension. Technical Report, No. 202. Urbana, IL: University of Illinois, (ERIC: 201992).

Girl, R. (1991). Dialogue and the Teaching of Reasoning. Educational Philosophy and Theory. Vol. 23(1):45-55.

Goodman, K. and C. Burke. (1973). Theoretically Based Studies of Patterns of Miscues in Oral Reading Performance. Washington, D. C.; U.S. Department of Health, Education and Welfare, Office of Education.

Goodman, K. S. (1976). Reading: A Psycholinguistic Guessing Game. In Singer, H., \& Ruddell, R.B. (Eds.), Theoretical Models and Processes of Reading (2nd ed., pp. 497-508). [Online] Available: https://uascentral.uas.alaska.edu/onlinelib/Fall-2007/ED674-JD1/Goodman_article.pdf

Grabe, W. (2009). Reading in a second language: Moving from theory to practice. New York: Cambridge University Press.

Grellet, F. (1981). Developing Reading Skills. Cambridge: Cambridge University Press.

Halliday, M. and R. Hasan. (1976). Cohesion in English. London: Longman.

Harmon, J., Elizabeth B. M.,\& Karen W. (2010). The Cognitive Vocabulary Approach to Word Learning. English Journal, 100(1), 100-107. (EJ896471)

Iwai, Y. (2009). Metacognitive Awareness and Strategy Use in Academic English Reading among Adult English as a Second Language (ESL) Students. Ph.D. Dissertation, University of Southern Mississippi. (ED513139)

Kabacali, A. (1997). Nasreddin Folk Narrative from Turkey. Middle East Technical University, P.xii.

Karbalaei, A. (2010). A Comparison of the Metacognitive Reading Strategies Used by EFL and ESL Readers. Reading Matrix: An International Online Journal, 10(2), 165-180. (EJ908518)

Khun, D. (2000). Metacognitive Development. Current Direction in Psychological Science, 9, 178-181.

Koda, K. (2005). Insights into second language reading: A cross-linguistic approach. New York: Cambridge University Press.

Kress, G. (1989). Linguistics Processes in Sociocultural Processes. Oxford: Oxford University Press.

Leavitt, Brynn C. (2010). How We Read between the Lines: Miscue Analysis as an Indicator of Metacognitive Strategy Use in Foreign Language Reading. Online Submission, Master Thesis, Indiana University South Bend. (ED510273). 
Lee, J. and B. VamPatten. (1995). Making Communicative Language Teaching Happen. New York: MacGraw-Hill, Inc.

Mackay, R., Barkman, B., and R. R. Jordan. (1979) Reading in a Second Language. New York: Newbury House Publications.

Munby, J. (1978). Communicative Syllabus Design. Cambridge: Cambridge University Press.

Noordman, L. and Vonk W. (1992). Readers' Knowledge and the Control of Inferences in Reading, In J. Oakhil and A. Gernham (Eds.). Discourse Representation and Text Processing. Hover: Laurence Erlbaum Associates, Publisher. (372-395).

Pearson, P. (Ed). (1984). Handbook of Reading Research. London: Longman.

Peker, B. (1998). Enjoying Predicting: Let it all Hang out, MAN! In The Second Inged-Gazi International ELT Conference Proceedings, 2-4, October, (240-250).

Plastina, A. F. (1997). Reading Strategies in L1 and L2: A case study of FL Secondary School Students in Calabria. Southern Italy. Unpublished Master's Thesis. University of Surrey. UK.

Schank, R. and Bustein M. (1985). Artificial Intelligence: Modeling Memory for Language Understanding, In Van Dijik (ed.). A Handbook of Discourse Analysis. Vol. 1. Ch. 6. New York: Academic Press.

Shanklin, N. (1981). Relating Reading and Writing: Developing a Transactional Theory of the Writing Process (Monograph in Language and Reading). School of Education, Indiana University.

Singhal, M. (1998). A Comparison of L1 and L2: Reading Cultural Differences and Schemata. [Online] Available: http://iteslj.org/Articles/Singhal-ReadingL1L2.html

Singhal, M. (2001). Reading Proficiency, Reading Strategies, Metacognitive Awareness and L2 Readers. The Reading Matrix. 1 (1). [Online] Available: http://www.readingmatrix.com/articles/singhal/

Smith, F. (1982). Understanding Reading ( $3^{\text {rd }}$ ed). New York: Holt, Rinehart, and Winston.

Spiro, R. (1977). Remembering Information from Text: The State of Schema Approach, In R. C. Anderson, R. J. Spiro, \& W. E. Montague (Eds.) Schooling and the Acquisition of knowledge. Hillsdale, NJ: Erlbaum. (pp. 137-165).

Tierney,K and Pearson P. (1983). Toward a Comparing Model of Reading. Language Arts, 60:568-680.

Van Dijik, T. (1976). Macrostructure, Knowledge Frames, and Discourse Comprehension. Paper contributed to the Carnegie-Mellon Symposium on Cognition.

Van Dijik, T. (1981). Review of R. O. Freedle (ed.) 1979. Journal of Linguistics, 17:140-8.

Voss, J., G. Vesonder and G. Spilich. (1980). Text Generation and Recall by High-Knowledge Subjects. Journal of Verbal Learning and Verbal Behavior. 19:651-667.

Widdowson, H. G. (1998). The Theory and Practice of Critical Discourse Analysis. Applied Linguistics, 19(1):136-151.

Yule, G. (1986). The Study of Language. Cambridge: Cambridge University Press. 